\title{
Observations of the radiation divergence in the surface layer and its implication for its parameterization in numerical weather prediction models
}

\author{
G. J. Steeneveld, ${ }^{1}$ M. J. J. Wokke, ${ }^{2}$ C. D. Groot Zwaaftink, ${ }^{3}$ S. Pijlman, ${ }^{4}$ \\ B. G. Heusinkveld, ${ }^{1}$ A. F. G. Jacobs, ${ }^{1}$ and A. A. M. Holtslag ${ }^{1}$ \\ Received 24 August 2009; revised 26 October 2009; accepted 3 November 2009; published 26 March 2010.
}

[1] This paper presents the results of 5 months of in situ observations of the diurnal cycle of longwave radiative heating rate in the lower part of the atmospheric boundary layer over grassland, with a particular focus on nighttime conditions. The observed longwave radiative heating is minimal at the evening transition, with a median value of $-1.8 \mathrm{~K} \mathrm{~h}^{-1}$ between 1.3 and $10 \mathrm{~m}$ and $-0.5 \mathrm{~K} \mathrm{~h}^{-1}$ between 10 and $20 \mathrm{~m}$, respectively. After the transition, its magnitude gradually decreases during the night. For individual clear calm nights, a minimal radiative heating rate of -3.5 and $-2.0 \mathrm{~K} \mathrm{~h}^{-1}$ was found for the two indicated layers. The total radiative heating rate appears dominantly controlled by the upward longwave flux divergence. Surprisingly, at noon a radiative heating rate of $\sim 1 \mathrm{~K} \mathrm{~h}^{-1}$ was found between 1.3 and $10 \mathrm{~m}$ for clear calm days. The availability of these radiation divergence measurements enables evaluation of the model performance for the temperature tendency caused by radiation divergence. The mesoscale model MM5 performs poorly for the stable boundary layer, because it overestimates the surface temperature and wind speed, while it underestimates the magnitude of radiative cooling. Some computationally efficient methods based on physical modeling, statistical modeling, and dimensional analysis are proposed by examining the gathered data set. The physical modeling approach appears to perform best.

Citation: Steeneveld, G. J., M. J. J. Wokke, C. D. Groot Zwaaftink, S. Pijlman, B. G. Heusinkveld, A. F. G. Jacobs, and A. A. M. Holtslag (2010), Observations of the radiation divergence in the surface layer and its implication for its parameterization in numerical weather prediction models, J. Geophys. Res., 115, D06107, doi:10.1029/2009JD013074.

\section{Introduction}

[2] The planetary boundary layer (PBL) over land experiences a clear diurnal cycle attributed to the diurnal cycle of incoming radiation. From the evening transition, the Earth's surface cools because of net longwave radiative loss. Consequently, the potential temperature increases with height, and a stable boundary layer (SBL) develops. The SBL is governed by a multiplicity of physical processes: turbulent mixing, radiative cooling, the interaction with the land surface, gravity waves, katabatic flows, fog and dew formation etc. Despite many research efforts, these processes and their interactions are insufficiently understood, because the diversity and the usual absence of stationarity inhibits unambiguous interpretation of observations [Mahrt, 2007]. Hence, this ambiguity hampers model parameterization development. As a result, the SBL is inadequately

\footnotetext{
${ }^{1}$ Meteorology and Air Quality Section, Wageningen University, Wageningen, Netherlands.

${ }^{2}$ Now at Meteogroup B.V., Wageningen, Netherlands.

${ }^{3}$ Now at WSL-Institut für Schnee- und Lawinenforschung SLF, Davos, Switzerland.

${ }^{4}$ Now at Royal Haskoning, Rotterdam, Netherlands.

Copyright 2010 by the American Geophysical Union. 0148-0227/10/2009JD013074
}

represented in atmospheric models for weather and climate [e.g., Beljaars and Viterbo, 1998; Dethloff et al., 2001; King et al., 2007; Gerbig et al., 2008; Bechtold et al., 2008; Walsh et al., 2008].

[3] Typical model errors for the SBL are the overestimation of the surface vegetation temperatures for calm nights [e.g., Steeneveld et al., 2008], although other models experience unrealistic decoupling of the atmosphere from the surface, resulting in so-called runaway surface cooling [e.g., Mahrt, 1998; Walsh et al., 2008]. The inconvenient model representation of the SBL results in evident problems for air quality prediction [Neu, 1995; Salmond and McKendry, 2005], $\mathrm{CO}_{2}$ inverse modeling studies [Geels et al., 2007], agricultural management [Prabha and Hoogenboom, 2008], and road traffic. Therefore, a better understanding and representation of the SBL is desirable.

[4] Once the SBL has developed, both turbulence and radiation will transport heat to overcome the temperature difference between the surface and the atmosphere. As such, the temperature tendency in the SBL (assuming horizontal homogeneity and negligible advection) reads as

$$
\frac{\partial \theta}{\partial t}=-\frac{\partial \overline{w \theta}}{\partial z}-\frac{1}{\rho C_{p}} \frac{\partial L^{*}}{\partial z}
$$


The two terms on the right-hand side represent vertical divergence of the turbulent heat flux $(\overline{w \theta})$ and net longwave radiation $\left(L^{*}\right)$, respectively, and $\rho$ and $C_{p}$ denote the density and specific heat capacity of air. This paper focuses on observations of the latter term near the surface (lowest $20 \mathrm{~m}$ ). We aim to analyze and quantify the longwave radiative heating rate (LHR) by means of observations over grass in midlatitudes and compare these with output of the fifth generation Pennsylvania State University-National Center for Atmospheric Research mesoscale model (MM5). Note that although MM5 is currently replaced by the Weather Research and Forecast (WRF) model, the radiation schemes in WRF are similar to the ones in MM5, and thus we expect similar model deficiencies. WRF indeed shows similar deficiencies as MM5 for comparable clear days in 2006 (not shown). Therefore, WRF and other models also can benefit from the current analysis. Also, we derive a practical, computationally efficient LHR parameterization for use in atmospheric models from the data set. Section 2 presents background information, and section 3 introduces the measurement site and setup. Section 4 presents observations and model results for a selected case, while section 5 covers a climatological analysis. Conclusions are drawn in section 6 .

\section{Background}

\subsection{Observations}

[5] Despite the expected importance of radiation during low winds, it is not studied very intensively, since most attention is paid to turbulence [e.g., Beljaars and Holtslag, 1991; Beare et al., 2006; Cuxart et al., 2006]. However, model deficiencies for the SBL are most prominent during calm conditions. In that case, the turbulence intensity is relatively low and turbulent heat exchanges are relatively small. As a result, other processes than turbulence take over the SBL development in a natural way, e.g., radiation divergence [Steeneveld et al., 2006].

[6] Vertical radiation divergence occurs at (steep) changes with height of the temperature or of the absorbing gas concentration. Since these changes occur close to the surface, we also expect the longwave radiative fluxes to diverge substantially near the surface. Formally speaking, the temperature tendency is also influenced by the horizontal radiative flux divergence. Although this term could possibly be important in heterogeneous areas, or close to buildings, we omitted this term from our analysis since our measurements were obtained in rather homogeneous conditions.

[7] Despite the recommendation by Zdunkowski and Johnson [1965] to pursue further research on the LHR in the SBL, only a limited number of studies are available. Stull [1988] pointed out that nighttime LHR can be either positive or negative, which indicates a lack of understanding on this process. The first observational studies by Funk [1960] and Fuggle and Oke [1976] reported an LHR of up to $-6.6 \mathrm{~K} \mathrm{~h}^{-1}$ between 0.5 and $1.5 \mathrm{~m}$ over grass. In contrast, Lieske and Stroschein [1967] found an LHR of $+5 \mathrm{~K} \mathrm{~h}^{-1}$ between 1 and $5 \mathrm{~m}$ over Arctic snow, and only a small LHR above $20 \mathrm{~m}$. Nunez and Oke [1976] extended this analysis for a city and reported a mean LHR of $-0.6 \mathrm{~K} \mathrm{~h}^{-1}$. Moreover, Nkemdirim [1978, 1988] found a mean LHR of
$-0.7 \mathrm{~K} \mathrm{~h}^{-1}$ in the lowest $10 \mathrm{~m}$ for prechinook events. $\mathrm{Li}$ et al. [1983] observed a typical LHR of -1.0 and $-2.1 \mathrm{~K} \mathrm{~h}^{-1}$ at 16 and $36 \mathrm{~m}$, respectively, with the strongest cooling at the top of a shallow surface inversion.

[8] The variability of the observed LHR originates from both technical limitations and observational difficulties that need to be overcome to obtain accurate results (e.g., dew formation on sensors, ventilation, bias correction, mast influence). The measurement uncertainties are typically close to the measured difference between the individual upwelling and downwelling longwave fluxes. Therefore, Duynkerke [1999] concluded that it is nearly impossible to measure the LHR in the lowest meters of the SBL. However, the high accuracy of the observed long-term LHR over Greenland by Hoch et al. [2007] (hereafter H07) motivated us to pursue further research.

[9] Many of the previously cited studies have the drawback that they cover only a few nights and a single atmospheric layer. Hoch [2005] and H07 showed yearround observations of the LHR over Greenland between the surface and $50 \mathrm{~m}$, and they examined its dependence on temperature gradient, surface humidity, and wind speed. H07 found a substantial diurnal cycle of the LHR, with $-1.5 \mathrm{~K} \mathrm{~h}^{-1}$ for calm nights. They concluded that the divergence of the upwelling radiation is the dominant contributor to the total LHR. Drüe and Heinemann [2007] reported 1 month of LHR observations over Greenland up to $800 \mathrm{~m}$ and found radiative cooling to be important under both calm and moderate wind speeds. In contrast, Estournel et al. [1986] found that longwave cooling is of secondary impact during the ECLATS (Etude de la Couche Limite Atmospherique Tropicale, Sèche, Niger, November 1980) experiment for nights with moderate winds. Sun et al. [2003] estimated an LHR of $-0.5 \mathrm{~K} \mathrm{~h}^{-1}$ between 48 and $2 \mathrm{~m}$ during the CASES-99 campaign over prairie grassland in Kansas (United States), although values up to $-2 \mathrm{~K} \mathrm{~h}^{-1}$ were recorded just after the evening transition.

[10] Apart from the results for the nocturnal period, the observations of Moores [1982] indicate that the LHR also plays an important role in the heat transport during the day, although convection is expected to dominate the heat transport at first glance. He found an LHR of $0.05-$ $0.52 \mathrm{~K} \mathrm{~h}^{-1}$ below $150 \mathrm{~m}$ ( $30 \%$ of the turbulent heating) and $0.06 \mathrm{~K} \mathrm{~h}^{-1}$ cooling above $150 \mathrm{~m}$. Thus, the general idea that the LHR is small during the day is too simple.

\subsection{Modeling}

[11] In addition to the experimental work, modeling efforts on the LHR have been performed by Funk [1961], Garratt and Brost [1981], Estournel and Guedalia [1985], André and Mahrt [1982], Räisänen [1996], and Ha and Mahrt [2003] (hereafter HM03). HM03 and Räisänen [1996] found a large sensitivity to model resolution; even the forecasted sign of the LHR can be wrong for coarse resolutions. Also, a full radiation scheme that accounts for all absorbing gases $\left(\mathrm{H}_{2} \mathrm{O}, \mathrm{CO}_{2}, \mathrm{O}_{3}, \mathrm{CH}_{4}\right.$, etc. $)$ at every grid cell and every time step is computationally too expensive for large-scale numerical weather prediction (NWP) and climate models. Therefore, these models typically call the radiation scheme at a low frequency (every $3 \mathrm{~h}$ or so), which influences the representation of the diurnal cycle [VilàGuerau de Arellano and Casso-Torralba, 2007]. Moreover, 


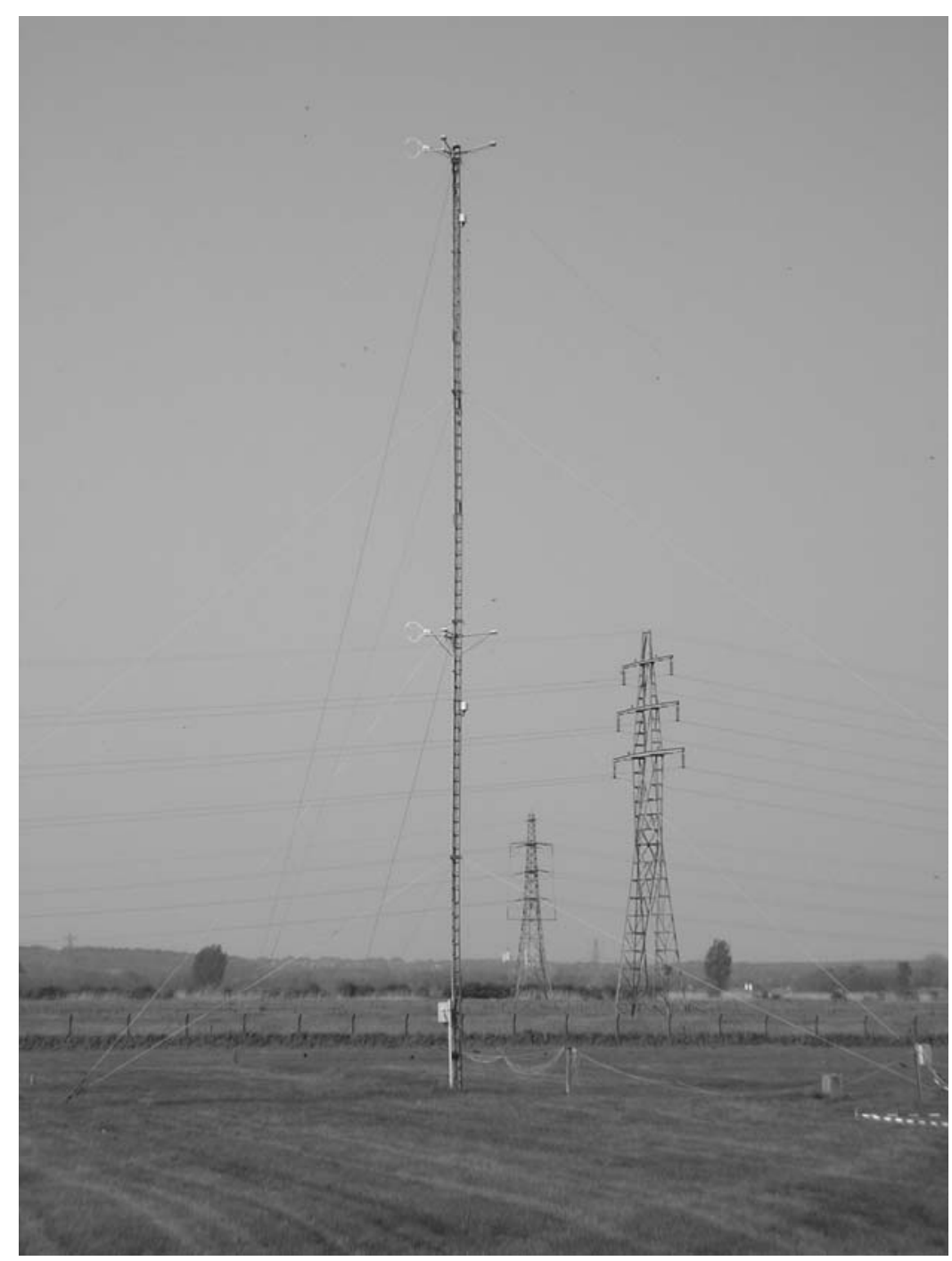

Figure 1. Experimental site with tower for radiation divergence observations in Wageningen, Netherlands (view is in western direction). Photo by Oscar Hartogensis.

these schemes have been calibrated and validated against the observed atmospheric cooling in the full atmospheric column. However, the SBL is very shallow with large temperature and humidity gradients, which can differ from free atmospheric gradients. Therefore, it is likely that radiation schemes as used in NWP models have not been calibrated for the SBL and do not correctly account for radiation in the SBL. Also, the calculated nighttime LHR differs among various radiation parameterizations, especially for calm conditions [Steeneveld et al., 2008]. At the same time, it is realized that a correct representation of radiative cooling might help to prevent NWP models from entering nonphysical decoupling since atmospheric radiative cooling will restrict the temperature difference between the atmosphere and the surface. Thus, we are in search of a simple parameterization for near-surface LHR in terms of available model variables.

\section{Materials and Methods}

[12] Wageningen University operates a routine meteorological observatory in Wageningen, Netherlands $\left(51.58^{\circ} \mathrm{N}\right.$, $5.38^{\circ} \mathrm{E}, 7 \mathrm{~m}$ above sea level [Jacobs et al., 2003, 2007]) (Figure 1). The area is covered with perennial species of ryegrass (Lolium perenne L.) and rough bluegrass (Poa trivialis L.). During the growing season (1 May to 1 November), the grass is mown approximately weekly, has a mean height of $0.1 \mathrm{~m}$, and has a mean leaf area index of 2.9. The soil consists predominantly of heavy basin clay. Some small heterogeneities are present because of ditches, different grass species at adjacent fields, electricity towers, and a farm $500 \mathrm{~m}$ ahead. An aspirated psychrometer measures the air temperature, $T_{1.5 m}$, and wet bulb temperature, $T_{w}$, at $1.5 \mathrm{~m}$. At $0.10 \mathrm{~m}$, the air temperature is measured with a shielded Pt-100 thermometer. The downwelling $\left(S^{\downarrow}\right)$ and upwelling $\left(S^{\uparrow}\right)$ shortwave radiation are measured with an aspirated pyranometer (Kipp \& Zonen, Delft, Netherlands, CM11) at $1.3 \mathrm{~m}$. At the same height, the downwelling $\left(L^{\downarrow}\right)$ and upwelling $\left(L^{\uparrow}\right)$ longwave radiation are measured with a pyrgeometer (Kipp \& Zonen, CG1). As additional measurements, we mounted two net longwave radiometers (Kipp \& Zonen, CG2) on a tower at 10 and $20 \mathrm{~m}$, during the period 1 February to 30 June 2006. 
Table 1. Slope, Offset, and Fraction Explained Variance of Relative Calibration of Radiation Sensors Versus the Sensors at $1.3 \mathrm{~m}$

\begin{tabular}{lcccc}
\hline & $L^{\downarrow} 10 \mathrm{~m}$ & $L^{\downarrow} 20 \mathrm{~m}$ & $L^{\uparrow} 10 \mathrm{~m}$ & $L^{\uparrow} 20 \mathrm{~m}$ \\
\hline Slope & 0.9498 & 0.9613 & 0.9976 & 1.0037 \\
Offset $\left(\mathrm{W} \mathrm{m}^{-2}\right)$ & 10.95 & 8.4415 & 0.2766 & -3.4707 \\
$R^{2}$ & 0.9984 & 0.9974 & 0.9958 & 0.9955 \\
\hline
\end{tabular}

[13] The flat silicon windows of the CG2 blocks solar radiation and transmits light in a spectral range from 4.5 to $42 \mu \mathrm{m}$ onto a thermopile sensor. The CG2 is equipped with two thermopile sensors to be able to measure both components separately. The flat window limits the field of view to $150^{\circ}$. The CG2 is factory calibrated outdoors against a pyrgeometer with a field of view of $180^{\circ}$, and therefore its output is representative at a typical weather station. The CG2 has a time constant of $8 \mathrm{~s}$, and its nonlinearity is less than $1 \%$ (within meteorological range) temperature dependence of sensitivity less than $-2 \%$ (at $-20^{\circ} \mathrm{C}$ or $50^{\circ} \mathrm{C}$ ). Observations were collected at $1 \mathrm{~Hz}$ and aggregated to 10 min mean values. Furthermore, all instruments were inspected on a daily basis and cleaned if necessary. For further information on the measurement principle for longwave radiation, see Philipona et al. [1995].

[14] After the experiment, all sensors were mounted at $1.3 \mathrm{~m}$ for 2 months (July and August 2006) and calibrated relative to each other (Table 1). The deviation of the instruments that were previously installed at 10 and $20 \mathrm{~m}$ from the instrument at $1.3 \mathrm{~m}$ appeared $\sim 10 \mathrm{~W} \mathrm{~m}^{-2}$ for $L^{\downarrow}$. This bias is probably caused by the sensor at $1.3 \mathrm{~m}$, which appeared not to be calibrated for much longer than recommended by the manufacturer. On the contrary, the sensors at 10 and $20 \mathrm{~m}$ worked properly during inspection by the manufacturer (after the experiment). However, we are interested in the measurement of a difference, and therefore the discovered bias (after relative calibration of the fluxes) does not influence our results. Consequently, the measurements during the experimental campaign were corrected for the observed bias. Subsequently, these bias-corrected fluxes are used to estimate the LHR between layer $i+1$ and $i$ as follows (expressed in $\mathrm{K} \mathrm{h}^{-1}$ ):

$$
\mathrm{LHR}=\frac{3600}{\rho C_{p}} \frac{L_{i+1}^{\downarrow}-L_{i+1}^{\uparrow}+L_{i}^{\uparrow}-L_{i}^{\downarrow}}{z_{i+1}-z_{i}},
$$

where $\rho$ is the air density and $C_{p}$ is the heat capacity of air at constant pressure.

[15] Besides uncertainties in the LHR of instrumental origin, specific atmospheric conditions also can hamper meaningful LHR observations. The following data selection has been applied to minimize these effects. Observations during wind speeds (at $10 \mathrm{~m}$ ) smaller than $1.5 \mathrm{~ms}^{-1}$ have been excluded from the analysis. This selection aims to ensure data analysis of sufficiently ventilated radiometers at 10 and $20 \mathrm{~m}$. Also, observations during rain or subject to rain in the previous $2 \mathrm{~h}$, or during fog events, or with a relative humidity of more than $97 \%$ were discarded to ensure the radiometers were dry.
[16] Drüe and Heinemann [2007] suggested estimating the measurement uncertainty of the LHR by the standard deviation of the recorded longwave flux for stationary conditions. Figure 2 shows the median (of $1 \mathrm{~h}$ observations) of the standard deviation for three diurnal cycles during clear skies and calm winds. The standard deviation of $L^{\downarrow}$ is relatively small, $\sim 0.4 \mathrm{~W} \mathrm{~m}^{-2}$, especially at night. In contrast, for $L^{\uparrow}$ the standard deviation is larger, but at night is still limited to $0.7 \mathrm{~W} \mathrm{~m}^{-2}$. However, to estimate a confidence interval for $L^{\downarrow}$ and $L^{\uparrow}$, one should realize that within a 10 min interval, the observations are correlated for $1 \mathrm{~Hz}$ measurements when the instrument response time is $8 \mathrm{~s}$. Therefore, we will utilize the method of $\mathrm{H} 07$, who determined their measurement uncertainty in the LHR from the flux residues after relative calibration. Thus, the bias that appeared between sensors during the calibration period has been removed by linear regression, and the statistical distribution of the residues serves as the basis for the measurement uncertainty.

[17] Although these residues are not exactly normally distributed, we use the standard deviation of these residues as the basis for our uncertainty estimation; in doing so, we find a standard deviation for $L^{\downarrow}$ and $L^{\uparrow}$ of $\sim 0.8 \mathrm{~W} \mathrm{~m}^{-2}$ and $\sim 1.0 \mathrm{~W} \mathrm{~m}^{-2}$, respectively. The uncertainty in the LHR was attributable to $L^{\downarrow}$ and $L^{\uparrow}$ amounts of 0.23 and $0.29 \mathrm{~K} \mathrm{~h}^{-1}$, respectively. In total, the uncertainty for the net flux differences amounts was $1.29 \mathrm{~W} \mathrm{~m}^{-2}$, which corresponds to $0.43 \mathrm{~K} \mathrm{~h}^{-1}$ for the LHR. These values correspond closely to those of $\mathrm{H} 07$.

[18] H07 pointed out that the observed $L^{\downarrow}$ and $L^{\uparrow}$ should be corrected for influence of the tower emission. We used the same correction method as $\mathrm{H} 07$ for our data set, but we found that the corrections were relatively small. First, this is due to the use of an open tower of only $30 \mathrm{~cm}$ side length, so the azimuth over which the tower was seen is small. Second, a relatively large part of the tower was not seen by the radiometers because of the instrument field of view of $150^{\circ}$. Keeping in mind the corrections, data selection, and uncertainty analysis, we obtained a reliable data set for the diurnal cycle of the LHR, which is suitable for further analysis.

\section{A Case Study \\ 4.1. Observations}

[19] Our analysis starts with three diurnal cycles with clear skies and weak winds, i.e., 10-12 May 2006. Figure 3 shows the median of the LHR between 1.3 and 10, 10-20, and $1.3-20 \mathrm{~m}$. It is evident that the LHR undergoes a clear diurnal cycle, peaks just after sunset (1920 UTC), and amounts to approximately $-3.5 \mathrm{~K} \mathrm{~h}^{-1}$ or even more between 1.3 and $10 \mathrm{~m}$. Between 10 and $20 \mathrm{~m}$, the LHR is limited to $-1.8 \mathrm{~K} \mathrm{~h}^{-1}$ after sunset, and its magnitude gradually decreases with time. Contrary to Sun et al. [2003], who showed that the LHR is a minor contributor to the temperature tendency in the remainder of the night, we find a substantial cooling. In fact, our findings correspond to those of $\mathrm{H} 07$, who reported a strong diurnal cycle of the LHR in summer, with the LHR between -0.4 and $-1.3 \mathrm{~K} \mathrm{~h}^{-1}$ between 2 and $48 \mathrm{~m}$. Also, Schaller [1977] found an LHR of -0.9 to $-1.7 \mathrm{~K} \mathrm{~h}^{-1}$ as maximum cooling for a site close to Munich. He even found that the radiative 

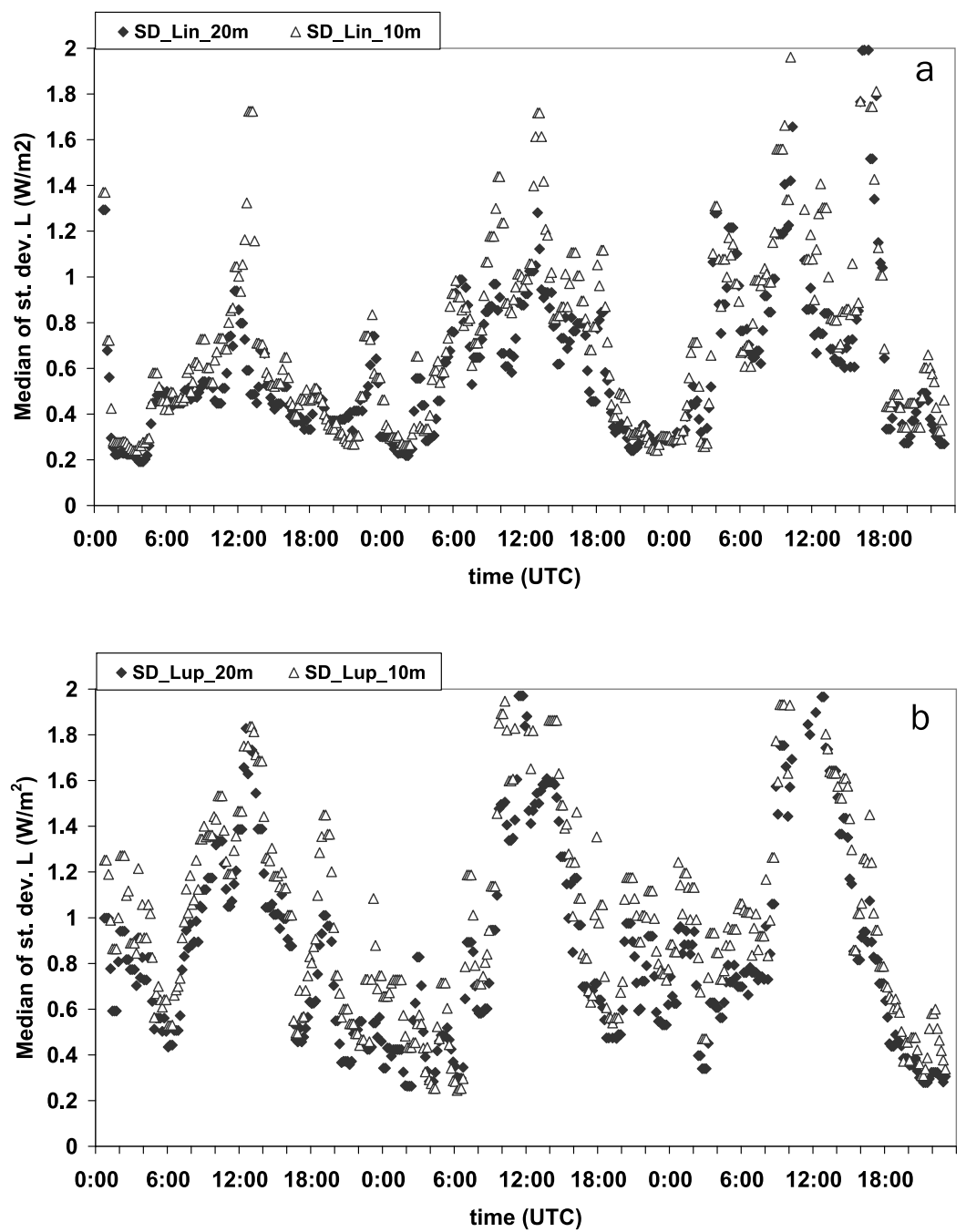

Figure 2. Hourly median of the 10 min-based standard deviation of (a) downwelling and (b) upwelling longwave radiation at $10 \mathrm{~m}$ (triangles) and $20 \mathrm{~m}$ (diamonds), for 10-12 May 2006 (DOY = 130-132).

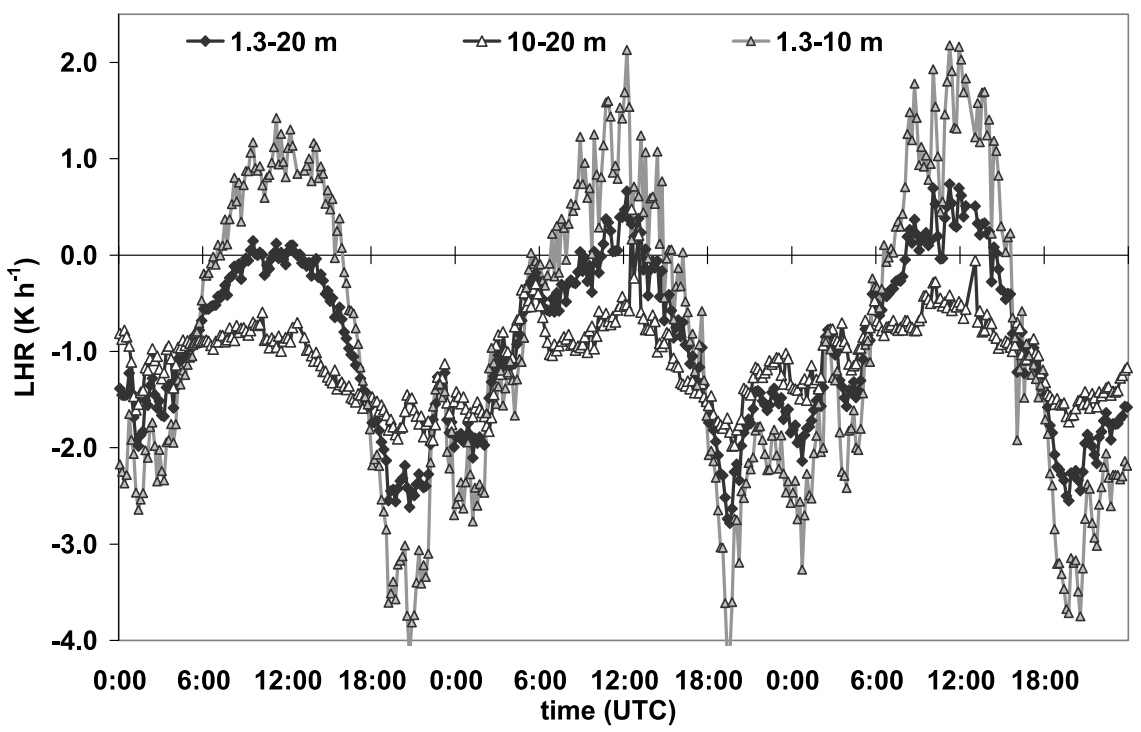

Figure 3. Time series of observed longwave radiative heating rate in the layers between 1.3 and 10 , 10 and 20 , and 1.3 and $20 \mathrm{~m}$. Observations are for DOY $130-132$ and $10 \mathrm{~min}$ averages. 

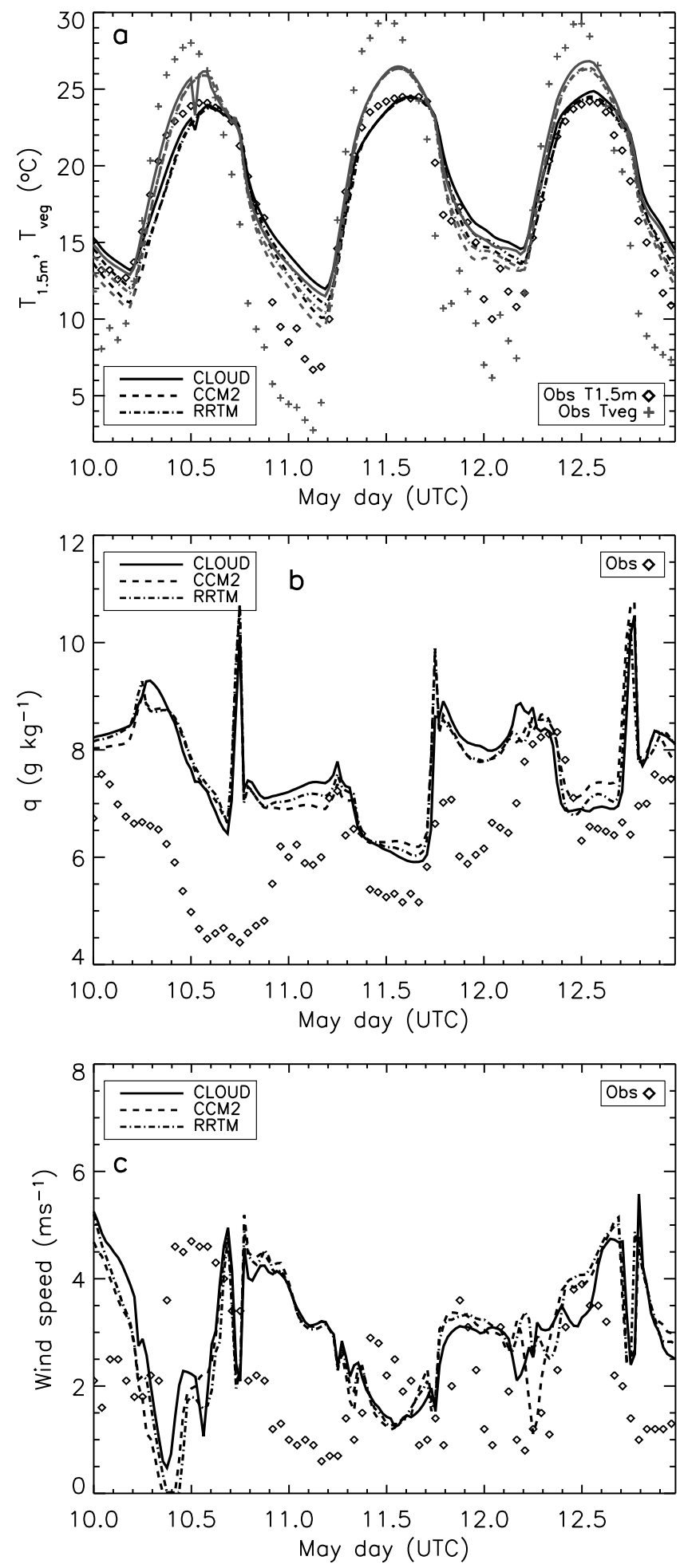

Figure 4. Modeled (MM5) and observed (a) screen and vegetation surface temperature, (b) specific humidity, and (c) wind speed for 10-13 May 2006 for Wageningen, Netherlands. In Figure 4a, the black lines indicate $T_{1.5} \mathrm{~m}$, and the gray lines indicate $T_{\text {veg }}$.

cooling exceeds cooling by the turbulent flux divergence at night. For a comparably calm day, model calculations by Savijärvi [2006] provided an LHR of approximately $-0.5 \mathrm{~K} \mathrm{~h}^{-1}$ between 1 and $10 \mathrm{~m}$, but LHR $>0$ closer to the ground. On the basis of high-resolution temperature and humidity profiles in CASES-99, HM03 modeled an LHR of -2.5 to $-6 \mathrm{~K} \mathrm{~h}^{-1}$ in the early evening for clear nights and $-1.5 \mathrm{~K} \mathrm{~h}^{-1}$ at midnight. Using a different model, Steeneveld et al. [2006] reported similar values for CASES-99. As such, our observational findings agree with the outcome of high-resolution radiation transfer models. Finally, as in previous studies, the total atmospheric cooling is less than the radiative cooling (not shown). This suggests that turbulent heating occurs close to the ground, which compensates the large radiative cooling [Tjemkes and Duynkerke, 1989].

[20] Although radiative transport in the convective PBL is often assumed to be small relative to the turbulent transport, we find an LHR of $1 \mathrm{~K} \mathrm{~h}^{-1}$ close to the surface for these days. Apparently, the ground surface reaches such a high temperature that the lowest atmospheric layer gains heat by radiation from the surface. Observations by Moores [1982] $\left(1 \mathrm{~K} \mathrm{~h}^{-1}\right)$ and $\mathrm{H} 07\left(0.63 \mathrm{~K} \mathrm{~h}^{-1}\right)$ and simulations by Savijärvi [2006] $\left(1.7 \mathrm{~K} \mathrm{~h}^{-1}\right)$ support these findings for calm days, although the heating is smaller for windy conditions.

\subsection{MM5 Model Results}

[21] It is interesting to evaluate the MM5 model results against our observations for radiation divergence. We have run MM5 (version 3.6) for the clear days above, using four nested domains of $31 \times 31$ nodes, utilizing a horizontal resolution of $27,9,3$, and $1 \mathrm{~km}$, respectively. The model's initial and boundary conditions are provided by the European Center for Medium Range Weather Forecasting (ECMWF) operational analysis every $6 \mathrm{~h}$, whereas the United States Geological Survey provided the land cover map. MM5 uses $35 \sigma$ levels, with nine layers in the lowest $350 \mathrm{~m}$, and with the first level at $\sim 18 \mathrm{~m}$. MM5 was run from 9 May 20061200 UTC to 13 May 20061200 UTC, of which the first $24 \mathrm{~h}$ are considered as spin-up, and these have been excluded from the analysis. We utilize the Medium Range Forecast boundary layer scheme [Troen and Mahrt, 1986] because of its advantageous behavior for clear sky daytime conditions. Finally, the MoninObukhov [Businger et al., 1971] surface layer scheme and the five-soil layer land-surface scheme have been selected.

[22] Following our interest in radiation, three permutations for the radiation scheme have been used: CLOUD, RRTM, and CCM2. The CLOUD scheme only considers the interaction of radiation with water vapor and $\mathrm{CO}_{2}$, whereas RRTM represents a detailed absorption spectrum of $\mathrm{CO}_{2}, \mathrm{CH}_{4}, \mathrm{NO}_{x}$, and $\mathrm{O}_{3}$. In $\mathrm{CCM} 2$, the longwave radiative effects of the greenhouse gases $\mathrm{CO}_{2}, \mathrm{O}_{3}, \mathrm{H}_{2} \mathrm{O}$, $\mathrm{CH}_{4}, \mathrm{~N}_{2} \mathrm{O}, \mathrm{CFC} 11$, and $\mathrm{CFC} 12$ are treated using broadband approximations, and an 18-band $\delta$-Eddington approximation is used for solar radiation. Further details on the different radiation schemes can be found in studies by Dudhia [1989], Mlawer et al. [1997], and Kiehl et al. [1998] for CLOUD, RRTM, and CCM2, respectively.

[23] The MM5 forecast corresponds well with screenlevel observations for $T_{1.5 \mathrm{~m}}$ during daytime (Figure 4a). However, it is clear that the model has difficulties in reproducing the nighttime $T_{1.5 \mathrm{~m}}$, and especially vegetation surface temperature $T_{v e g}$ during the full diurnal cycle. For the night of 10/11 May 2006, the forecasted $T_{1.5 \mathrm{~m}}$ and $T_{v e g}$ are $\sim 6 \mathrm{~K}$ too warm, and the same holds for the night of 


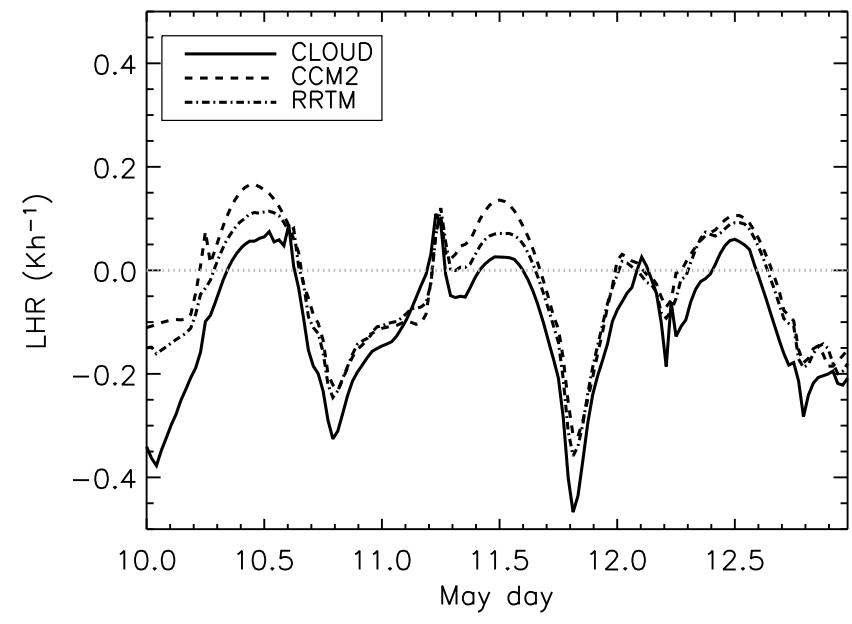

Figure 5. Time series of modeled LHR in the lowest $18 \mathrm{~m}$ for the CLOUD, CCM2, and RRTM schemes in MM5, for 10 May 2006, 0000 UTC to 13 May 2006, 0000 UTC.

12/13 May. For 11/12 May, the performance is better, although $T_{\text {veg }}$ is still overestimated, since this night is slightly less stable than the other nights. Moreover, note that the warming and cooling in MM5 lags behind the observations. The permutations of the same MM5 run for different radiation schemes provides only small differences of $1-2 \mathrm{~K}$ at night, with the largest deviations before sunrise. This variability is approximately similar for $T_{1.5}$ and $T_{v e g}$. Note that Steeneveld et al. [2008] found a larger sensitivity ( $T_{\text {veg }}$ differences of $\sim 3.5 \mathrm{~K}$ ) between radiation schemes for three consecutive nights over prairie grass in the CASES-99 campaign. A possible explanation for this difference are the dry conditions in CASES-99 with a specific humidity $(q)$ of $\sim 2-4 \mathrm{~g} \mathrm{~kg}^{-1}$, while in this study, $q$ ranges from 4.2 to $8.2 \mathrm{~g} \mathrm{~kg}^{-1}$ (Figure $4 \mathrm{~b}$ ). Apparently, the MM5 results are more sensitive to the choice of the radiation scheme in dry conditions than in humid conditions. On the other hand, the current model results confirm for CASES-99 that the CLOUD scheme provides the warmest nights and CCM2 provides the coldest nights. At the same time, MM5 has difficulties to reproduce nearsurface $q$ (too humid). The evident peak of $q$ just before the evening transition on 10 May is caused by a modeled sea breeze front that approaches Wageningen, although the modeled front does not pass this location. However, this approach temporarily influences the flow such that modeled dry and moist air alternate.

[24] MM5 overestimates the wind speed during evening transition, which provides enhanced turbulence and thus increased evaporation, also leading to a high $q$. At night, the wind speed has typically been overestimated, thereby overestimating turbulent heat transport to the surface, leading to the warm temperature bias. In addition, a positive $q$ bias will support a larger $L^{\downarrow}$ and thus impede surface cooling. Finally, note that the slow response of the first soil layer (Figure 4a) also contributes to the warm bias and needs further attention in model development and evaluation. It should be noticed here that the model results represent a grid scale average and the observations represent a point, and as such, the evaluation is not completely fair. Unfortunately, area- averaged observations are unavailable. However, the model shows similar deficiencies as in previous studies in which area-averaged observations were indeed available.

[25] For all radiation schemes, the magnitude of the calculated LHR between the surface and $\sim 18 \mathrm{~m}$ is very small compared to the observations (Figure 5), with only $-0.4 \mathrm{~K} \mathrm{~h}^{-1}$ at sunset. Model output corresponds with the observations that LHR is minimal at the evening transition and is slowly increasing during the remainder of the night. Generally speaking, the observed LHR is 1 order of magnitude larger than its modeled counterpart. A Student's $t$ test confirmed that all schemes provide significantly different LHRs than the observations $\left(p<1.10^{-8}\right.$ for a $95 \%$ confidence interval). In general, the CLOUD scheme forecasts the smallest LHR, although the difference with the other schemes is relatively small. HM03 explained that the LHR is very important in the onset of the surface inversion. As such, its slow onset in MM5 could be related to the poor representation of LHR. Finally, note that MM5 forecasts much smaller LHR values at noon $\left(\sim 0.1 \mathrm{~K} \mathrm{~h}^{-1}\right)$ than has been observed $\left(\sim 1 \mathrm{~K} \mathrm{~h}^{-1}\right)$.

[26] MM5 has been rerun with an improved SBL scheme [Steeneveld et al., 2008], with reduced turbulent mixing and with an introduced surface vegetation layer. These modifications improved the model skill for $T_{v e g}$, friction velocity $(u *)$ and SBL height in CASES-99. With CLOUD, the LHR increases in the morning transition for this setup, but differences are minor at night (not shown). In contrast, with CCM2 and RRTM, the LHR doubles at night with the modified scheme, although it remains smaller than observed. The most evident result with the modified SBL scheme is an increased temporal LHR variability, which is closer to reality, considering the temporal variability in Figure 3.

[27] In general, the MM5 results could be sensitive to the initial and boundary conditions. Therefore, we examine the robustness of the MM5 results by performing a sensitivity test. As a first experiment, the soil moisture availability $(\theta)$ has been varied from 0.15 to 0.6 (dimensionless), which is a reasonable range for grass. In a second experiment, the roughness lengths for heat and momentum $\left(z_{0}\right)$ were varied between $0.03 \mathrm{~m}$ and $0.50 \mathrm{~m}$. These experiments reveal a relatively small sensitivity of the LHR for these boundary conditions (Figure 6). The general pattern of the LHR is similar as in the reference runs (Figure 5), especially at night. During daytime, the modeled LHR is slightly sensitive to $z_{0}$, where a small (large) $z_{0}$ results in a slightly larger (smaller) LHR. A smaller $z_{0}$ will provide a higher $T_{v e g}$ and thus a larger temperature difference between the surface and the atmosphere and a larger LHR in order to transport heat away from the surface. The model sensitivity for $\theta$ shows a similar pattern as for $z_{0}$ (Figure 6b). During daytime, a low $\theta$ results in a larger LHR, while the LHR is approximately similar as for the reference runs and does not fall below $-0.5 \mathrm{~K} \mathrm{~h}^{-1}$. With a high $\theta$, the minimum LHR is slightly compared to the reference run, as seen during the evening transition of 11 May.

[28] The small sensitivity for $\theta$ and $z_{0}$ indicates that the model deficiency for the LHR does not originate from the boundary conditions but suggests that the model deficiency results from either a shortcoming in the radiation schemes 

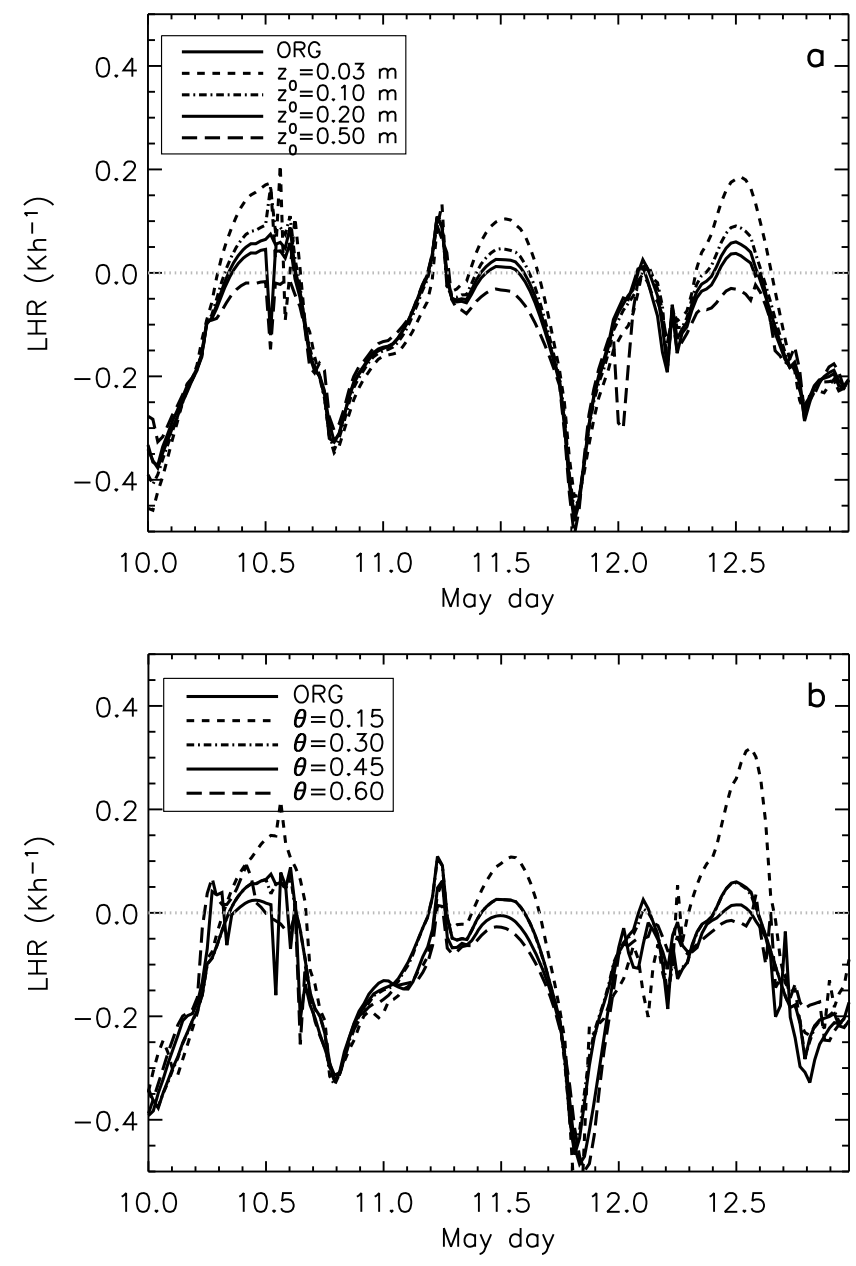

Figure 6. As in Figure 5 but for different values of (a) roughness length, $z_{0}$, and (b) soil moisture availability, $\theta$. For all runs, the CLOUD radiation scheme was used.

or from insufficient vertical resolution operational forecasts, or a combination of both.

[29] To examine a possible influence of initial conditions on the MM5 results, the initial field as provided by the ECMWF has been verified against radio sounding observations in De Bilt, Netherlands. This verification showed good correspondence with the observations. In addition, the +12 and +24 h MM5 forecast (during spin-up) shows excellent skill in the lowest kilometers for potential temperature and humidity, with errors smaller than $1 \mathrm{~K}$ and $1 \mathrm{~g} \mathrm{~kg}^{-1}$.

[30] Four runs have been performed in which the initial field for temperature and relative humidity have each been increased and decreased by $2 \mathrm{~K}$ and $10 \%$ in the lowest $2 \mathrm{~km}$. Both values are typical values for uncertainties in reanalysis fields [e.g., Kistler et al., 2001; Langland et al., 2008]. The runs indicate that the modeled LHR is not very sensitive to these permutations and thus that the shortcomings in the modeled LHR are persistent.

[31] To conclude, a mainstream NWP model has difficulties with forecasting wind, temperature, and LHR near the surface in the SBL. These findings motivate further study on the LHR and further development of radiation schemes to overcome these deficiencies.

\section{Climatological Results and Analysis}

\subsection{Basic Results}

[32] To further quantify the LHR in the SBL, and to examine the generality of the observations, we expand our data analysis from three golden days to a climatology over the full data set (Figure 7). The median value of the recorded LHR is indeed minimal after sunset and amounts to approximately $-1.8 \mathrm{~K} \mathrm{~h}^{-1}$ in the lowest layer, and its magnitude gradually reduces during the night. The LHR over the upper layer amounts to only $-0.5 \mathrm{~K} \mathrm{~h}^{-1}$ at sunset, and the radiative cooling is thus concentrated near the surface. If one assumes a Gaussian distribution for the bin-averaged LHR, then the mean of the bin-averaged LHR confidence interval amounts to $0.30 \mathrm{~K} \mathrm{~h}^{-1}$, while the median of the bin-averaged LHR confidence interval amounts to $0.17 \mathrm{~K} \mathrm{~h}^{-1}$. As such, the recorded LHR differs significantly from 0 . The smaller climatological cooling rate compared with the selected golden days corresponds with findings by $\mathrm{H} 07$, who found a cooling rate typically twice as large for calm than for windy conditions. Finally, note that LHR $\cong 0$ at noon in this long-term record (not shown), which indicates that radiative heating is limited to clear calm days [Hoch, 2005].

[33] It is important to realize that the distance over which the LHR is calculated control the result (Figure 3). In our study, radiative cooling dominates near the surface but is already small between 10 and $20 \mathrm{~m}$. This might explain the contradicting results in the literature, since the documented LHR has been measured over different height intervals. For example, for CASES-99 the LHR was estimated between 2 and $48 \mathrm{~m}$, although it is likely that the upper half of this layer hardly contributes to the cooling [HM03]. Furthermore, Savijärvi [2006] and Edwards [2009] found a char-

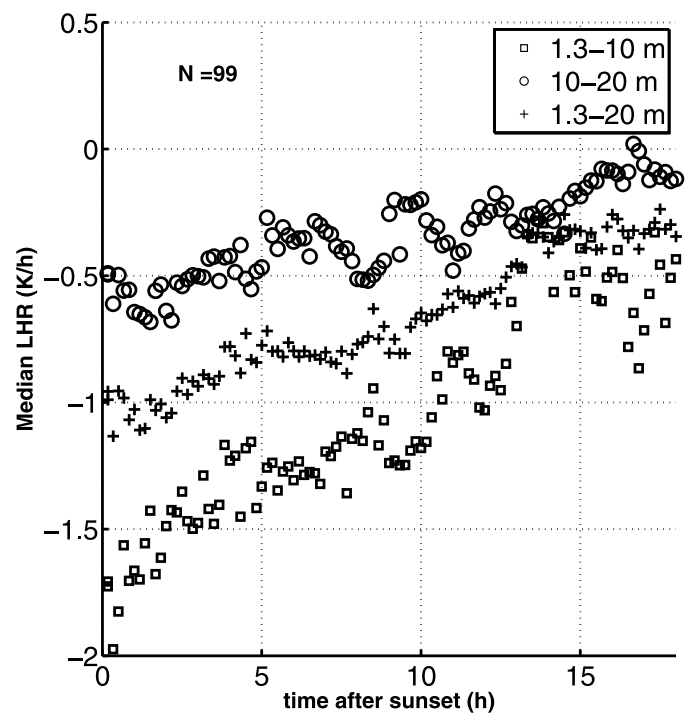

Figure 7. Observed median (based on 99 nights between February and June) of the measured radiative cooling for the diurnal cycle over $1.3-10,10-20$, and $1.3-20 \mathrm{~m}$. 

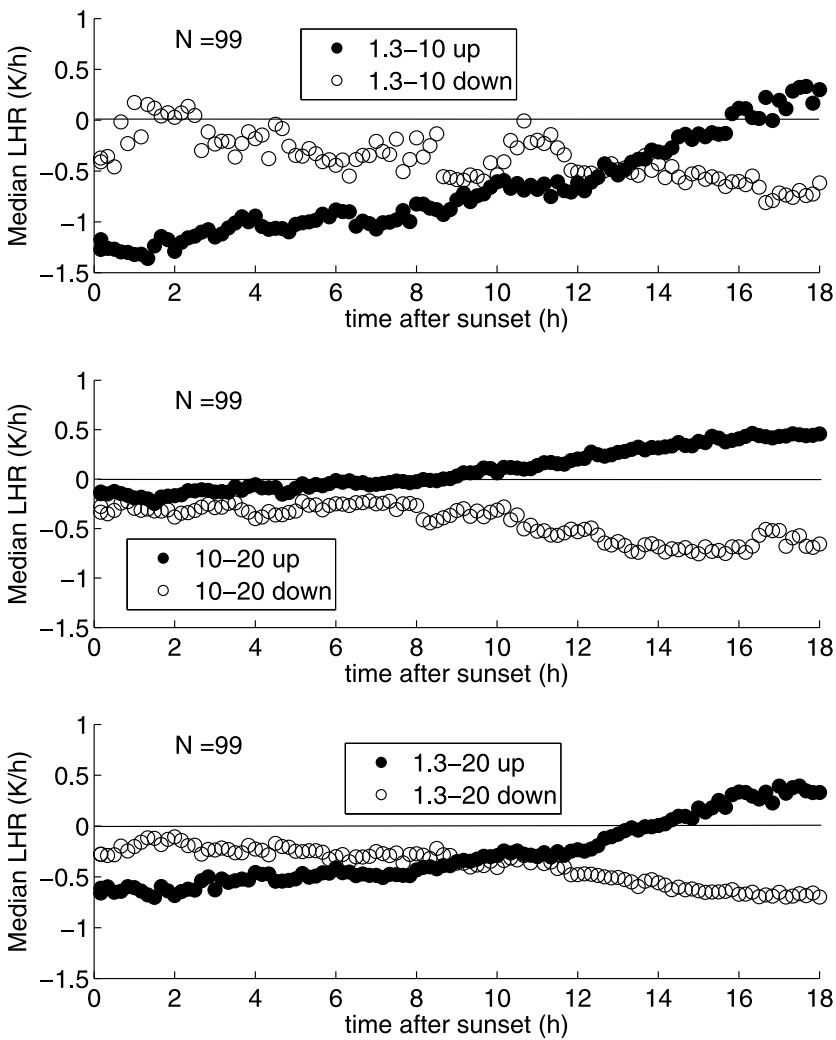

Figure 8. Observed median (based on 99 cases between February and June) of the diurnal cycle of radiation divergence for the upwelling and downwelling radiation for the layers over $1.3-10,10-20$, and $1.3-20 \mathrm{~m}$.

acteristic vertical profile for the LHR: heating occurs very close to the ground, the maximum cooling starts in a shallow layer between 1 and $10 \mathrm{~m}$, and this layer evolves upward in time. Substantially smaller cooling is found aloft. Because of this typical profile, one should be careful with the choice of the measurement heights.

[34] Figure 8 shows the same graph as Figure 3, but for the individual flux components. We find that $\nabla_{z} L^{\uparrow}$ dominates the total nighttime cooling, as was found by $\mathrm{H} 07$ and HM03. In the layer between 10 and $20 \mathrm{~m}$, a slight daytime heating by $\nabla_{z} L^{\uparrow}$ is counteracted by cooling by $\nabla_{z} L^{\downarrow}$ (Figure 8, middle).

[35] To summarize, our analysis shows that the LHR, as represented by different schemes in MM5, needs improvement. The remainder of the paper explores different semiempirical methods in search of a computationally efficient LHR parameterization in NWP models.

\subsection{Statistical Analysis}

[36] First investigate which variables can statistically explain the LHR. HM03 showed that the LHR relates linearly to the so-called temperature slip $\Delta T=T_{0.1 \mathrm{~m}}-T_{v e g}$ and is linear in $q$ and in the vertical temperature curvature $\left(\nabla_{z}^{2} T\right)$. In this study, $\nabla_{z}^{2} T$ was determined from the observations at $0.1,1.5$, and $10 \mathrm{~m}$. To the author's knowledge, it is the first time that these relations can be established based on field observations over grassland. Note, however, that despite our data selection, the temperature differences can $\mathrm{be}$, in principle, influenced by differences in degree of ventilation in the field. However, Figure 9 indicates that our field observations confirm the HM03 model results. Despite the relatively large uncertainties of the LHR, $\nabla_{z}^{2} T$, and $T_{v e g}$ in $\Delta T$, the relations between the LHR and the selected variables is evident. The correlation coefficient between the LHR and $q, \nabla_{z}^{2} T$, and $\Delta T$ amounts to -0.81 , 0.68 , and -0.80 , respectively. On the other hand, $\nabla_{z} q$ could, in principle, serve as an alternative humidityrepresenting variable, but its correlation coefficient with the LHR is only -0.57 , and $\nabla_{z} q$ has therefore been excluded from the following analysis. Note that $T_{\text {veg }}$ for this analysis was based on the observed $L_{s f c}^{\uparrow}$ and $L_{s f c}^{\downarrow}$, and assuming a surface emissivity $\varepsilon_{\mathrm{s}}=0.98$.

[37] Since this analysis relates meteorological variables that are difficult to measure accurately in the circumstances that we focus on (low winds, SBL), we limit our analysis to day of year $=160-180$. This period has been selected to avoid inhomogeneities in the data set because of mowing events and the advantageous weather conditions (i.e., calm winds, clear skies). Numerical coefficients of the statistical and dimensional analysis (see below) appeared sensitive to the mowing events. Reliable estimates for these coefficients could only be established for periods between mowing events. Mowing results in sudden changes of $z_{0}$, leaf area index (LAI), and $\varepsilon_{\mathrm{s}}$, and $\Delta T$ cannot be determined accurately. Thus, in principle, the LAI could be added as a relevant variable as well. However, LAI measurements, already difficult itself, are unavailable for the current campaign. Also, the derived $\varepsilon_{\mathrm{s}}$ varied substantially throughout 2006 (from 0.92 to 1.0), which affects $\Delta T$, and data analysis for a selected period is preferred. Finally, $\nabla_{z}^{2} T$ between 20 and $1.5 \mathrm{~m}$ cannot be determined with sufficient confidence, and therefore we only use $\nabla_{z}^{2} T$ between 10 and $0.1 \mathrm{~m}$.

[38] Multivariate linear regression for the LHR (in $\mathrm{K} \mathrm{h}^{-1}$ ) for $1.3-10 \mathrm{~m}$ and the variables listed above $\left(q, \nabla_{z}^{2} T\right.$, and $\Delta T$ ) leads to

LHR $=-216( \pm 58) q-0.725( \pm 1.16) \nabla_{z}^{2} T-0.079( \pm 0.090) \Delta T$

which was fitted with $R^{2}=0.96$, with $q$ in $\mathrm{kg} \mathrm{kg}^{-1}$, with $\Delta T$ in $\mathrm{K}$, and with $\nabla_{z}^{2} T$ in $\mathrm{K} \mathrm{m}^{-2}$. Note that the standard errors for the individual parameters are relatively large and that the relation between LHR and $q$ can be established with the largest confidence. Of course, the current linear model is only valid for the ranges of the input variables for which this regression has been derived, i.e., $7.5<q<13.5 \mathrm{~g} \mathrm{~kg}^{-1}$, $3.0<\Delta T<9.5 \mathrm{~K}$, and $-0.65<\nabla_{z}^{2} T<-0.28 \mathrm{~K} \mathrm{~m}^{-2}$.

[39] Evaluation of the proposed regression against the observations that were excluded during the model fitting shows poor forecast skill for equation (3). Apparently, the selected data for the model fitting are indeed not representative for the full data set. The disappointing result motivates us to further evaluate a physically based LHR model.

\subsection{Physical Model Results}

[40] As an alternative for the previous statistical method, we consider a simplified scheme for the longwave radiation difference $\Delta L$ between an atmospheric level and the surface [Coantic and Seguin, 1971]. The scheme is based on the 

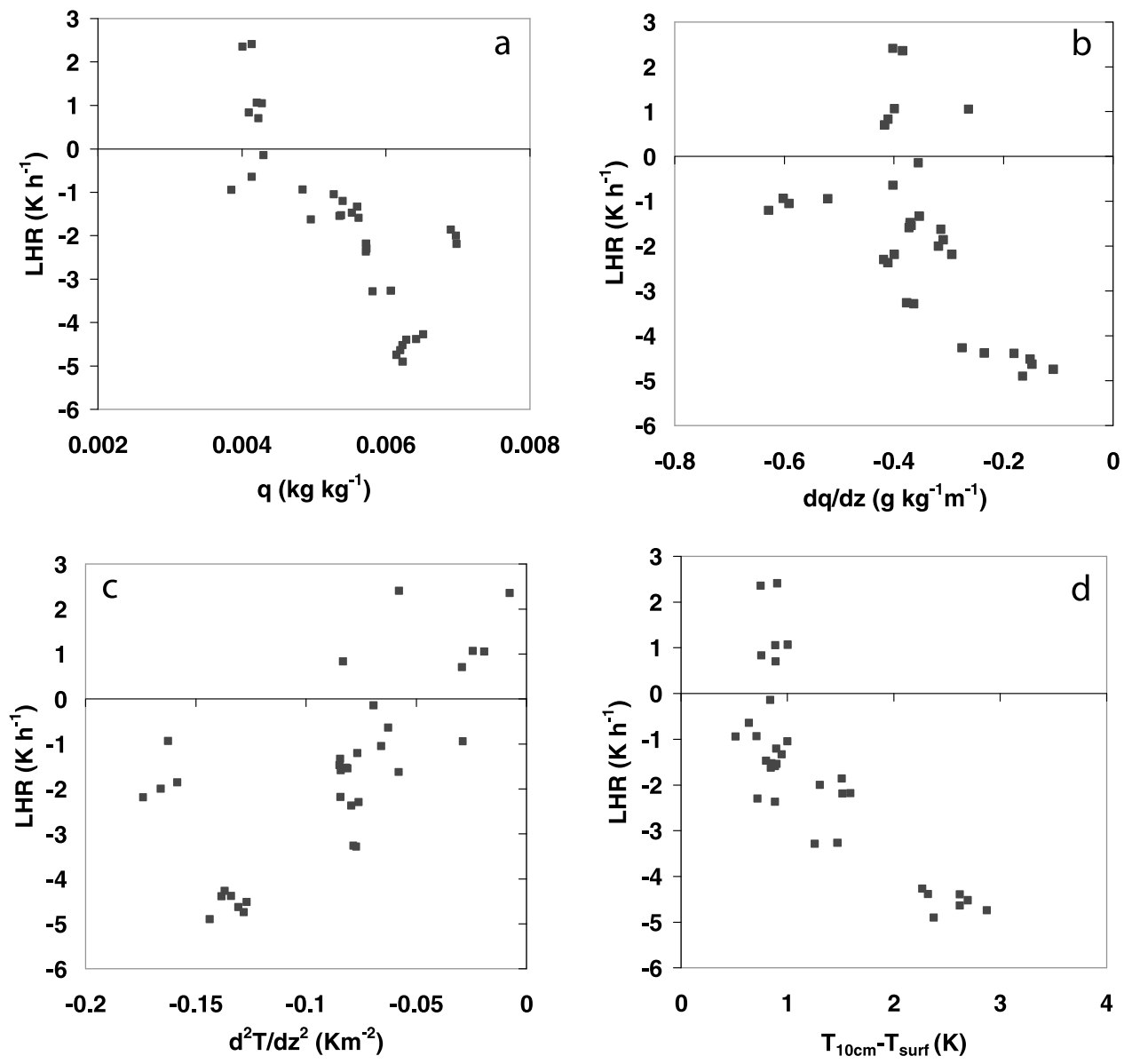

Figure 9. Observed radiative heating versus (a) specific humidity $q(r=-0.81)$, (b) specific humidity gradient $\mathrm{d} q / \mathrm{d} z(r=-0.57)$, (c) curvature of the temperature profile $(r=0.68)$, and (d) temperature slip $(r=-0.80)$.

radiative transport equations and on the potential temperature and specific humidity profile (assuming logarithmic profiles in the atmospheric surface layer):

$$
\begin{aligned}
& \Delta L= \\
& \quad 4 \sigma T_{0}^{3}\left\{\varepsilon(w)\left[\left(T_{0}-T_{v e g}\right)+\theta * \ln \frac{w}{w_{0}}\right]+\theta_{*}\left(R_{2}(w)-R_{2}\left(w_{0}\right)\right)\right\} .
\end{aligned}
$$

Here $T_{0}$ and $T_{\text {veg }}$ are the surface air and surface vegetation temperature, respectively; $\varepsilon$ is the atmospheric emissivity for water vapor path $w$; and $w_{0}$ is the water vapor path between the surface and $z_{0}$ for heat. $R_{2}$ is an empirical function based on laboratory experiments and accounts for absorption with height. Furthermore, $\theta_{*}=-\bar{w} \theta / u_{*}$. This method is computationally efficient and suitable to update the radiative tendency at higher frequency in NWP models. Using equation (4), we can calculate $\Delta L$ between $10 \mathrm{~m}$ and the surface and between $1.3 \mathrm{~m}$ and the surface. Subtracting these values provides an estimate for the LHR between 1.3 and $10 \mathrm{~m}$. For the selected period, the performance of the scheme seems reasonable $(r=0.73$, index of agreement is 0.84 ), especially considering the large measurement uncertainties (Figure 10). The large scatter for the night might be the result of the difficulty in observing $\theta_{*}$ and $q_{*}$ for calm conditions. Though the assumption of logarithmic profiles in the derivation of equation (4) is not a priori valid for very stable conditions, some studies [e.g., Duynkerke, 1999] suggest that the nondimensional temperature gradient $\varphi_{\mathrm{T}}(z / L)$ levels off to a constant value for $z / L \rightarrow \infty$, which

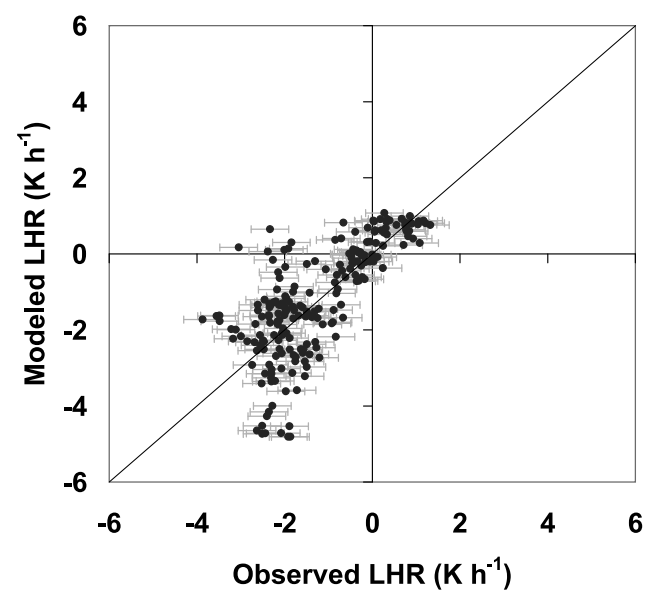

Figure 10. Observed radiation divergence between 1.3 and $10 \mathrm{~m}$ for DOY 160-180 compared with estimates by the scheme of Coantic and Seguin [1971]. 


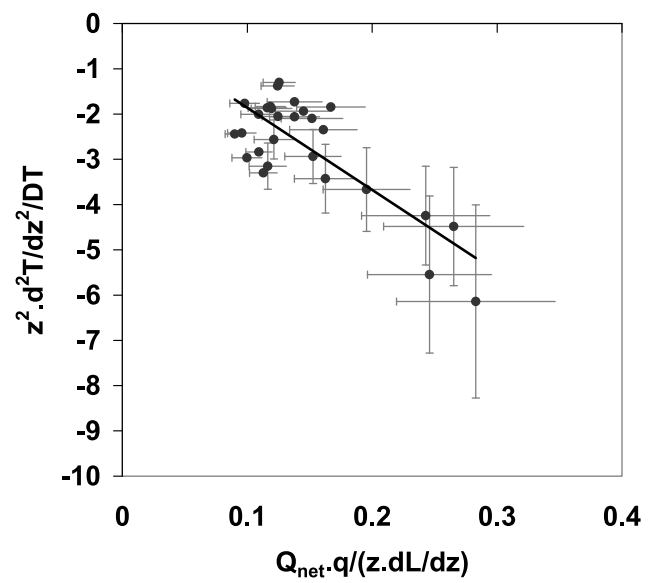

Figure 11. Observed relation between dimensionless groups $\Pi_{1}=\frac{z^{2} \nabla_{z}^{2} T}{\Delta T}$ and $\Pi_{2}=\frac{Q^{*} q}{z \partial L^{*} / \partial z}$ for DOY $160-180$. The linear regression reads $y \stackrel{z \partial L}{=}-18.13 x-0.05, R^{2}=$ 0.6387 .

implies a logarithmic temperature profile shape for $z / L \rightarrow \infty$, rather than a linear profile as predicted by the $z$-less scaling. Hence, the assumption of a logarithmic profile seems reasonable.

\subsection{Dimensional Analysis}

[41] Finally, we apply dimensional analysis to derive possible relations between the variables that govern the LHR. This technique is based on the Buckingham $\Pi$ theorem [e.g., Langhaar, 1951] and has shown success in boundary layer meteorology [e.g., Businger et al., 1971; Steeneveld et al., 2007]. In brief, the method identifies the number of relevant variables to a certain physical problem $(m)$ and the number of formal dimensions $(n)$ in the selected variables. Then $N=m-n$ dimensionless groups can be formed, and their mutual relations should be fitted from field observations. If this relation holds for all locations and atmospheric conditions, the obtained relation is also universal.

[42] We have selected the following six relevant variables: $z, Q^{*}, L H R, \Delta T, \nabla_{z}^{2} T$, and $q$. These six variables contain four fundamental units, thus two dimensionless groups can be constructed:

$$
\Pi_{1}=\frac{Q^{*} q}{z \frac{\partial L^{*}}{\partial z}} \text {, and } \Pi_{2}=\frac{z^{2} \nabla_{z}^{2} T}{\Delta T}
$$

The relation between $\Pi_{1}$ and $\Pi_{2}$ is approximately linear for the selected period, the standard errors are reasonably constrained, and a functional form can be established with satisfactory confidence (Figure 11). Also, $\Pi_{1}$ and $\Pi_{2}$ do not share variables (only constant height is considered), so the established relation is free from self-correlation [e.g., Baas et al., 2006], which yields confidence in our findings. Although not particularly surprising, a cross-validation also revealed that the achieved functional form is able to make useful estimates for the LHR using $z, Q^{*}, \Delta T, \nabla_{z}^{2} T$, and $q$ as inputs. For other periods in the data set, linear relations between $\Pi_{1}$ and $\Pi_{2}$ also could be established, although with a (much) different slope. Therefore, the current result indicates that dimensional analysis could be a useful technique for model development, but that a universal function cannot be retrieved from the current data set.

[43] To summarize, although the evaluated models show some skill, their disadvantages dissuade direct introduction into MM5, and further research (e.g., additional LHR observations at higher resolution at the surface) is required.

\section{Conclusions}

[44] This paper quantifies the longwave radiation divergence in the atmospheric surface layer over grass in the Netherlands by means of observations. We conclude that longwave radiative cooling is a relatively important contributor to the temperature budget during calm nights. The radiative heating rate undergoes a substantial diurnal cycle, is minimal at sunset, amounts to approximately $-1.8 \mathrm{~K} \mathrm{~h}^{-1}$ in the layer between 1.3 and $10 \mathrm{~m}$, and gradually increases with time. Between 10 and $20 \mathrm{~m}$, the recorded longwave radiative heating rate was $-0.5 \mathrm{~K} \mathrm{~h}^{-1}$ at sunset. We also conclude that near-surface radiative heating is substantial at noon for clear calm summer days. In addition, it was found that all radiation schemes in the MM5 mesoscale model underestimate the longwave radiative heating rate in the surface layer by approximately a factor 10 . This clear difference indicates further model improvement is needed.

[45] Several attempts were made to parameterize radiative heating in a simplified way, using either statistical or physical estimates, or dimensional analysis. We conclude that the estimation based on a physical method is overall the most reliable method. However, we also conclude that its skill is insufficient for direct introduction into MM5 and further research is required.

[46] Acknowledgments. We thank the technical staff of our department for the calibration and maintenance of the instrumentation during the experiment. This work was partly supported by the Dutch Climate Changes Spatial Planning program, Project BSIK-ME1, and Project BSIK-ME2. Finally, we thank our colleague, Leo Kroon, for his valuable comments on a previous version of this manuscript.

\section{References}

André, J. C., and L. Mahrt (1982), The nocturnal surface inversion and influence of clear-air radiative cooling, J. Atmos. Sci., 39, 864-878, doi:10.1175/1520-0469(1982)039<0864:TNSIAI $>2.0 . C O ; 2$.

Baas, P., G. J. Steeneveld, B. J. H. van de Wiel, and A. A. M. Holtslag (2006), Exploring self-correlation in flux-gradient relationships for stably stratified conditions, J. Atmos. Sci., 63, 3045-3054, doi:10.1175/ JAS3778.1.

Beare, R., et al. (2006), An intercomparison of Large-Eddy Simulations of the stable boundary layer, Boundary Layer Meteorol., 118, 247-272, doi:10.1007/s10546-004-2820-6.

Bechtold, P., M. Köhler, T. Jung, F. Doblas-Reys, M. Letbecher, M. J. Rodwell, R.Vitart, and G. Balsamo (2008), Advances in simulating atmospheric variability with the ECMWF model: From synoptic to decadal time-scales, Q. J. R. Meteorol. Soc., 134, 1337-1351, doi:10.1002/ qj. 289.

Beljaars, A. C. M., and A. A. M. Holtslag (1991), Flux parameterization over land surfaces for atmospheric models, J. Appl. Meteorol., 30, $327-$ 341, doi:10.1175/1520-0450(1991)030<0327:FPOLSF >2.0.CO;2.

Beljaars, A. C. M., and P. Viterbo (1998), Role of the boundary layer in a numerical weather prediction model, in Clear and Cloudy Boundary Layers, edited by A. A. M. Holtslag and P. G. Duynkerke, pp. 287304, R. Neth. Acad. Arts Sci., Amsterdam.

Businger, J. A., J. C. Wyngaard, Y. Izumi, and E. F. Bradley (1971), Flux profile relationships in the atmospheric surface layer, J. Atmos. Sci., 28 , 181-189, doi:10.1175/1520-0469(1971)028<0181:FPRITA >2.0.CO;2. 
Coantic, M., and B. Seguin (1971), On the interaction of turbulent and radiative transfers in the surface layer, Boundary Layer Meteorol., 1 , 245-263, doi:10.1007/BF02186030.

Cuxart, J., et al. (2006), A single-column model intercomparison for a stably stratified atmospheric boundary layer, Boundary Layer Meteorol., 118, 273-303, doi:10.1007/s10546-005-3780-1.

Dethloff, K., C. Abegg, A. Rinke, I. Hebestadt, and V. F. Romanov (2001), Sensitivity of Arctic climate simulations to different boundary-layer parameterizations in a regional climate model, Tellus, Ser. A, 53A, 1-26, doi:10.1034/j.1600-0870.2001.01073.x.

Drüe, C., and G. Heinemann (2007), Characteristics of intermittent turbulence in the upper stable boundary layer over Greenland, Boundary Layer Meteorol., 124, 361-381, doi:10.1007/s10546-007-9175-8.

Dudhia, J. (1989), Numerical study of convection observed during the winter monsoon experiment using a mesoscale two-dimensional model, J. Atmos. Sci., 46, 3077-3107, doi:10.1175/1520-0469(1989)046<3077. NSOCOD $>2.0 . C O ; 2$.

Duynkerke, P. G. (1999), Turbulence, radiation and fog in Dutch stable boundary layers, Boundary Layer Meteorol., 90, 447-477, doi:10.1023/A:1026441904734.

Edwards, J. (2009), Radiative processes in the stable boundary layer: Part I. Radiative aspects, Boundary Layer Meteorol., 131, 105-126, doi:10.1007/s10546-009-9364-8.

Estournel, C., and D. Guedalia (1985), Influence of geostrophic wind on atmospheric nocturnal cooling, J. Atmos. Sci., 42, 2695-2698, doi:10.1175./1520-0469(1985)042<2695:IOGWOA>2.0.CO;2.

Estournel, C., R. Vehil, and D. Guedalia (1986), An observational study of radiative and turbulent cooling in the nocturnal boundary layer (ECLATS experiment), Boundary Layer Meteorol., 34, 55-62, doi:10.1007/ BF00120908.

Fuggle, R. F., and T. R. Oke (1976), Long-wave radiative flux divergence and nocturnal cooling of the urban atmosphere, Boundary Layer Meteorol., 10, 113-120, doi:10.1007/BF00229279.

Funk, J. P. (1960), Measured radiative flux divergence near the ground at night, Q. J. R. Meteorol. Soc., 86, 382-389, doi:10.1002/ qj.49708636910.

Funk, J. P. (1961), A numerical method for the computation of the radiative flux divergence near the ground, J. Meteorol., 18, 388-392, doi:10.1175/ 1520-0469(1961)018<0388:ANMFTC $>2.0 . C O ; 2$

Garratt, J. R., and R. A. Brost (1981), Radiative cooling effects within and above the nocturnal boundary layer, J. Atmos. Sci., 38, 2730-2746, doi:10.1175/1520-0469(1981)038<2730:RCEWAA >2.0.CO;2.

Geels, C., et al. (2007), Comparing atmospheric transport models for future regional inversions over Europe-Part 1: Mapping the atmospheric $\mathrm{CO}_{2}$ signals, Atmos. Chem. Phys., 7, 3461-3479.

Gerbig, C., S. Körner, and J. C. Lin (2008), Vertical mixing in atmospheric tracer transport models: Error characterization and propagation, Atmos. Chem. Phys., 8, 591-602.

Ha, K. J., and L. Mahrt (2003), Radiative and turbulent fluxes in the nocturnal boundary layer, Tellus, Ser. A, 55A, 317-327, doi:10.1034/ j.1600-0870.2003.00031.x.

Hoch, S. W. (2005), Radiative flux divergence in the surface boundary layer-A study based on observations at Summit, Greenland, Ph.D. thesis, 181 pp., ETH, Zürich, Switzerland.

Hoch, S. W., P. Calanca, R. Philipona, and A. Ohmura (2007), Year-round observation of long-wave radiative flux divergence in Greenland, J. Appl. Meteorol. Climatol., 46, 1469-1479, doi:10.1175/JAM2542.1.

Jacobs, A. F. G., B. G. Heusinkveld, and A. A. M. Holtslag (2003), Carbon dioxide and water vapour flux densities over a grassland area in The Netherlands, Int. J. Climatol., 23, 1663-1675, doi:10.1002/joc.959.

Jacobs, A. F. G., B. G. Heusinkveld, and A. A. M. Holtslag (2007), Towards closing the surface energy budget of a mid-latitude grassland, Boundary Layer Meteorol., 126, 125-136, doi:10.1007/s10546-0079209-2.

Kiehl, J. T., J. J. Hack, G. B. Bonan, B. A. Boville, D. L. Williamson, and P. J. Rasch (1998), The National Center for Atmospheric Research Community Climate Model: CCM3, J. Clim., 11, 1131-1149, doi:10.1175/ 1520-0442(1998)011<1131:TNCFAR>2.0.CO;2.

King, J. C., A. Jrrar, and W. M. Connolly (2007), Sensitivity of modelled atmospheric circulation to the representation of the stable boundary layer processes, Geophys. Res. Lett., 34, L06708, doi:10.1029/2006GL028563.

Kistler, R., et al. (2001), The NCEP-NCAR 50-year reanalysis: Monthly means CD-ROM and documentation, Bull. Am. Meteorol. Soc., 82, $247-$ 267, doi:10.1175/1520-0477(2001)082<0247:TNNYRM>2.3.CO;2.

Langhaar, H. L. (1951), Dimensional Analysis and Theory of Models, 166 pp., Wiley, New York.

Langland, R. H., R. N. Maue, and C. H. Bishop (2008), Uncertainty in atmospheric temperature analyses, Tellus, Ser. A, 60, 598-603, doi:10.1111/j.1600-0870.2008.00336.x.
Li, X. S., J. E. Gaynor, and J. C. Kaimal (1983), A study of multiple stable layers in the nocturnal lower atmosphere, Boundary Layer Meteorol., 26, 157-168, doi:10.1007/BF00121540.

Lieske, B. J., and L. A. Stroschein (1967), Measurements and radiative flux divergence in the Arctic, Arch. Meteorol. Geophys. Bioklimatol., Ser. B, 15, 67-81, doi:10.1007/BF02319112.

Mahrt, L. (1998), Stratified atmospheric boundary layers and breakdown of models, Theor. Comp. Fluid Dyn., 11, 263-279, doi:10.1007/ s001620050093.

Mahrt, L. (2007), The influence of nonstationarity on the turbulent fluxgradient relationship for stable stratification, Boundary Layer Meteorol., 125, 245-264, doi:10.1007/s10546-007-9154-0.

Mlawer, E. J., S. J. Taubman, P. D. Brown, M. J. Iacono, and S. A. Clough (1997), Radiative transfer for inhomogeneous atmospheres: RRTM, a validated correlated-k model for the longwave, J. Geophys. Res., 102(D14), 16,663-16,682, doi:10.1029/97JD00237.

Moores, W. H. (1982), Direct measurements of radiative and turbulent flux convergences in the lowest $1000 \mathrm{~m}$ of the convective boundary layer, Boundary Layer Meteorol., 22, 283-294, doi:10.1007/BF00120010.

$\mathrm{Neu}$, U. (1995), A parameterization of the nocturnal ozone reduction in the residual layer by vertical downward mixing during summer smog situations using sodar data, Boundary Layer Meteorol., 73, 189-193, doi:10.1007/BF00708937.

Nkemdirim, L. (1978), A comparison of radiative and actual nocturnal cooling rates over grass and snow, J. Appl. Meteorol., 17, 1643-1646, doi:10.1175/1520-0450(1978)017<1643:ACORAA > 2.0.CO;2.

Nkemdirim, L. (1988), Nighttime surface-layer temperature tendencies with and without Chinooks, J. Appl. Meteorol., 27, 482-489, doi:10.1175/ 1520-0450(1988)027<0482:NSLTTW>2.0.CO;2.

Nunez, M., and T. R. Oke (1976), Long-wave radiative flux divergence and nocturnal cooling of the urban atmosphere, Boundary Layer Meteorol., 10, 121-135, doi:10.1007/BF00229280

Philipona, R., C. Fröhlich, and C. Betz (1995), Characterization of pyrgeometers and the accuracy of atmospheric long-wave radiation measurements, Appl. Opt., 34, 1598-1605, doi:10.1364/AO.34.001598.

Prabha, T., and G. Hoogenboom (2008), Evaluation of the weather research and forecasting model for two frost events, Comput. Electron. Agric., 64 234-247, doi:10.1016/j.compag.2008.05.019.

Räisänen, P. (1996), The effect of vertical resolution on clear-sky radiation calculations: Test with two schemes, Tellus, Ser. A, 48A, 403-423, doi:10.1034/j.1600-0870.1996.t01-2-00004.x.

Salmond, J. A., and I. G. McKendry (2005), A review of turbulence in the very stable boundary layer and its implications for air quality, Prog. Phys. Geogr., 29, 171-188, doi:10.1191/0309133305pp442ra.

Savijärvi, H. (2006), Radiative and turbulent heating rates in the clear-air boundary layer, Q. J. R. Meteorol. Soc., 132, 147-161, doi:10.1256/qj.05.61.

Schaller, E. (1977), Time and height variability of the sensible heat flux in the surface layer, Boundary Layer Meteorol., 11, 329-354, doi:10.1007/ BF02186085.

Steeneveld, G. J., B. J. H. van de Wiel, and A. A. M. Holtslag (2006), Modeling the evolution of the atmospheric boundary layer coupled to the land surface for three contrasting nights in CASES-99, J. Atmos. Sci., 63, 920-935, doi:10.1175/JAS3654.1.

Steeneveld, G. J., B. J. H. van de Wiel, and A. A. M. Holtslag (2007), Diagnostic equations for the stable boundary-layer height: Evaluation and dimensional analysis, J. Appl. Meteorol. Climatol., 46, 212-225, doi:10.1175/JAM2454.1.

Steeneveld, G. J., T. Mauritsen, E. I. F. de Bruijn, J. Vilà-Guerau de Arellano, G. Svensson, and A. A. M. Holtslag (2008), Evaluation of limited area models for the representation of the diurnal cycle and contrasting nights in CASES99, J. Appl. Meteorol. Climatol., 47, 869-887, doi:10.1175/2007JAMC1702.1.

Stull, R. B. (1988), An Introduction to Boundary Layer Meteorology, 666 pp., Kluwer Academic, Dordrecht, Netherlands.

Sun, J., S. P. Burns, A. C. Delany, S. P. Oncley, T. W. Horst, and D. H. Lenschow (2003), Heat balance in the nocturnal boundary layer during CASES-99, J. Appl. Meteorol., 42, 1649-1666, doi:10.1175/15200450(2003)042<1649:HBITNB>2.0.CO;2.

Tjemkes, S. A., and P. G. Duynkerke (1989), The nocturnal boundary layer: Model calculations compared with observations, J. Appl. Meteorol., 28, $161-175$, doi:10.1175/1520-0450(1989)028<0161:TNBLMC $>2.0$. CO;2. Troen, I. B., and L. Mahrt (1986), A simple model of the atmospheric boundary layer; sensitivity to surface evaporation, Boundary Layer Meteorol., 37, 129-148, doi:10.1007/BF00122760.

Vilà-Guerau de Arellano, J., and P. Casso-Torralba (2007), The radiation and energy budget in mesoscale models: An observational study case, Física de la tierra, 19, 117-132.

Walsh, J. E., W. L. Chapman, V. Romanovsky, J. H. Christensen, and M. Stendel (2008), Global climate model performance over Alaska and Greenland, J. Clim., 21, 6156-6174, doi:10.1175/2008JCLI2163.1. 
Zdunkowski, W. G., and F. G. Johnson (1965), Infrared flux divergence calculations with newly constructed radiation tables, J. Appl. Meteorol., 4, 371-377, doi:10.1175/1520-0450(1965)004<0371:IFDCWN>2.0. $\mathrm{zCO} ; 2$.

C. D. Groot Zwaaftink, WSL-Institut für Schnee- und Lawinenforschung SLF, Flüelastr. 11, CH-7260 Davos, Switzerland. (groot@slf.ch)
B. G. Heusinkveld, A. A. M. Holtslag, A. F. G. Jacobs, and G. J. Steeneveld, Meteorology and Air Quality Section, Wageningen University, P.O. Box 47, NL-6700 AA Wageningen, Netherlands. (Gert-Jan.Steeneveld@ wur.nl)

S. Pijlman, Royal Haskoning, PO Box 8520, NL-3009 AM Rotterdam, Netherlands. (s.pijlman@royalhaskoning.com)

M. J. J. Wokke, Meteogroup B.V., PO Box 617, NL-6700 AP Wageningen, Netherlands. (wokke@weer.nl) 